\title{
Review Article \\ On the RET Rearrangements in Chernobyl-Related Thyroid Cancer
}

\author{
Sergei V. Jargin \\ Department of Pathology, Peoples' Friendship University of Russia, Clementovski Per 6-82, Moscow 115184, Russia \\ Correspondence should be addressed to Sergei V. Jargin, sjargin@mail.ru
}

Received 6 June 2011; Accepted 11 October 2011

Academic Editor: Yasuhiro Ito

Copyright () 2012 Sergei V. Jargin. This is an open access article distributed under the Creative Commons Attribution License, which permits unrestricted use, distribution, and reproduction in any medium, provided the original work is properly cited.

\begin{abstract}
There is a consensus that Chernobyl accident has induced thyroid cancer increase in children and adolescents. The UNSCEAR report concluded that no somatic disorders other than thyroid cancer were caused by radiation exposure due to the accident except for acute radiation sickness occurred to the people within the Power Plant at the time of the accident. A hypothesis is discussed in this paper that the increase of thyroid cancer was caused predominantly by the screening, overdiagnosis, and registration of nonirradiated persons as Chernobyl victims. A mechanism of thyroid cancer overdiagnosis is described that can be active even today, causing hypertherapy. Older neglected tumors found by the screening shortly after the Chernobyl accident or brought from noncontaminated areas were misclassified as aggressive radiation-induced cancers. Therefore, supposed markers of the radiationinduced thyroid cancer, such as the RET rearrangements, are probably associated with disease duration and tumor progression. The screening effect is obviously dependent on the basis level of medical surveillance: the higher the level, the smaller the screening effect. Absence of any significant increase of thyroid cancer after the Fukushima accident in spite of the vigorous screening would certify the high level of health care in Japan especially for children.
\end{abstract}

In some publications $[1,2]$, cause-effect relationships between radiation, certain genetic abnormalities, and incidence increase of the post-Chernobyl thyroid cancer (TC) are treated as proven facts. It was even assumed that elevated radiation background and medical exposures could have contributed to the TC incidence increase in some countries [3]. The possibility that the post-Chernobyl TC increase was largely caused by factors irrelevant to ionizing radiation was discussed previously [4-9]. Outdated equipment of laboratories in the early 1990s and insufficient quality of histological specimens hindered reliable histopathological examination. Access to foreign professional literature has been limited in the former Soviet Union. High tumor expectancy after the accident contributed to overdiagnosis of cancer. Appearance of advanced tumors shortly after the accident can be explained by a screening effect with detection of old undiagnosed cancers, and by the fact that patients from noncontaminated areas were registered as Chernobyl victims. Some of such cases were classified as aggressive radiogenic cancers developing after a short latency.
Accordingly, some features of supposedly radiogenic TC must characterize, on average, a later stage of the tumor progression. For example, chromosomal rearrangements of the tyrosine kinase proto-oncogenes RET, the RET/PTC3 in particular, found in high proportion in papillary TC (PTC) of patients exposed during childhood and adolescence $[10,11]$, were discussed as possible markers of radiogenic cancer $[2,12]$. Over time, percentage of tumors with $R E T$ rearrangements declined, while among $R E T$-positive tumors the percentage with $R E T / P T C 1$ increased and RET/PTC3 decreased $[10,11]$. The RET/PTC3 rearrangements were the most frequent ones during the "first wave" of PTC after the Chernobyl accident, while RET/PTC1 seems to have predominated in cases with longer latency [13]. Old neglected cancers must have been particularly frequent among the early cases, when the pool of undiagnosed tumors was still untapped, equipment of histopathological laboratories not yet modernized, and post-Chernobyl radiophobia was at its apogee. The first wave PTC must have been on average "older" than those detected later [9]; accordingly, the former 
tumors were generally larger than the latter ones [14]. Furthermore, it was pointed out that RET rearrangements in the post-Chernobyl papillary PTC were associated with "increased aggressiveness in terms of pathological stage" $\left(\mathrm{pT}_{4}\right.$ in particular) at the disease onset [15]. Considering uncertainties in regard to the disease onset, from this statement remains a quintessence: RET rearrangements in PTC were associated with increased aggressiveness in terms of pathological stage, the latter, in its turn, being naturally associated with disease duration. Moreover, it would be logical to assume that increased aggressiveness in terms of pathological stage would be associated with that in terms of histologic grade. It is therefore not surprising that the cancers developing after short latency were found to be "significantly less structurally differentiated" than later ones [14].

It is sometimes objected that screening cannot account for the age-related differences; there has been no clearly demonstrated increase in the incidence of cancers due to radiation from Chernobyl accident, except for the TC among patients exposed at a young age $[16,17]$. In fact, there is an explanation: children at schools and kindergartens are easily available for screening; mass examinations of children and adolescents were performed by not always perfectly trained teams, under the conditions of high tumor expectancy. The following citations from a Russian-language professional publication provide some insight (verbatim from Russian): "Practically all nodular thyroid lesions, independently of their size, were regarded at that time in children as potentially malignant tumors, requiring an urgent surgical operation" or "Aggressiveness of surgeons contributed to the shortening of the minimal latency period" [18]. Although there was some overdiagnosis [5], many therapy-demanding cancers were successfully detected, so that the benefit from screening certainly prevailed. The role of screening (its ability to enhance registered TC incidence many times), of latent and dormant carcinomas [19] and tumors of uncertain malignant potential in overestimation of the post-Chernobyl TC incidence were discussed previously [5]. One of the mechanisms leading to overdiagnosis is as follows. If a thyroid nodule is found by screening, a fineneedle aspiration is usually performed. Aspiration cytology of the thyroid is accompanied by relatively high percentage of uncertain conclusions (so-called grey zone), when histological verification is indicated. Hemithyroidectomy or subtotal thyroidectomy was usually performed in such cases, and the surgical specimen was forwarded to a pathologist, who could be sometimes prone, after the in toto removal of the nodule, to confirm malignancy even in case of some uncertainty [6]. Our article describing this mechanism, possibly causing overdiagnosis and hypertherapy of TC even today, was rejected by the journal Arkhiv Patologii. Peculiarities of pediatric material added their share to uncertainty. The Head pediatric oncologist of Russian Federation professor Vladimir Poliakov pointed out shortage of cytologists, especially those having experience with pediatric material (personal communication, 2009). Foreign handbooks and atlases of cytology were seldom at working places. Note that indications for thyroidectomy on the basis of cytology alone should always be carefully considered, taking into account quality of cytological examination.

It was demonstrated that RET rearrangements can be induced by radiation in animal experiments and in vitro [20-22], but the doses were considerably higher than those in the setting of the Chernobyl accident. Correlations of $R E T / P T C$ rearrangements with radiation doses were found retrospectively among atomic bomb survivors in Japan [23, 24]. It is perfectly possible that $R E T / P T C$ rearrangements can be induced by ionizing radiation; however, in case of Chernobyl, as discussed above, the molecular-genetic features of the PTC were probably determined, in the first place, by factors other than radiation. Furthermore, high prevalence of RET/PTC rearrangements and reciprocally low prevalence of BRAF mutations were described as hallmarks of sporadic childhood PTC, unrelated to radiation [13]. Accordingly, it was assumed that the "waves" of PTC after the Chernobyl accident (first RET/PTC3, then RET/PTC1, and the third wave of $B R A F$-mutated PTC) represent a recapitulation of the age-related sequence observed in sporadic PTC [13]. The matter could be further clarified by correlation of RET rearrangements with disease duration, tumor size, histologic grade, and certain tumor phenotypes. An association of RET-PTC3 with the less differentiated solid phenotype of PTC, which prevailed shortly after the accident, has already been demonstrated $[11,14]$. It is in accordance with the hypothesis that the "first wave" tumors had on average higher histological grade because they were generally older and more advanced than those detected at a later date. In conclusion, the RET rearrangements, the RET/PTC3 in particular, were probably related to the disease duration and a corresponding stage of tumor progression, and the "successive waves of tumors in those exposed to high levels of fallout as children, each with different molecular, morphological, and clinical findings" [10] after the Chernobyl accident were largely determined by changing approach to screening and diagnostics, their improvement with time, and exhaustion by screening of the pool of undiagnosed cancers. Finally, a short comment with regard to the nuclear plant accident in Fukushima after the greatest earthquake in the Japanese history is presented. The screening effect is obviously dependent on the basis level of medical surveillance: the higher the level, the smaller the screening effect. I am not well informed about conditions in Japan, but probably the basis level of medical checkups has been high and there will be no false registration of nonirradiated persons as victims of the Fukushima accident. There can be some increase of the registered TC after the accident due to the health examinations vigorously initiated in the Fukushima area, but it will be much less prominent than that after the Chernobyl accident. Absence of any significant increase of TC after the Fukushima accident in spite of the screening would certify the high level of health care in Japan especially among children and adolescents.

\section{References}

[1] M. Gandhi, V. Evdokimova, and Y. E. Nikiforov, "Mechanisms of chromosomal rearrangements in solid tumors: the 
model of papillary thyroid carcinoma," Molecular and Cellular Endocrinology, vol. 321, no. 1, pp. 36-43, 2010.

[2] Y. E. Nikiforov, J. M. Rowland, K. E. Bove, H. MonforteMunoz, and J. A. Fagin, "Distinct pattern of ret oncogene rearrangements in morphological variants of radiation-induced and sporadic thyroid papillary carcinomas in children," Cancer Research, vol. 57, no. 9, pp. 1690-1694, 1997.

[3] Y. E. Nikiforov, "Is ionizing radiation responsible for the increasing incidence of thyroid cancer?" Cancer, vol. 116, no. 7, pp. 1626-1628, 2010.

[4] S. V. Jargin, "Over-estimation of radiation-induced malignancy after the Chernobyl accident," Virchows Archiv, vol. 451, no. 1, pp. 105-106, 2007.

[5] S. V. Jargin, "Thyroid carcinoma in children and adolescents resulting from the Chernobyl accident: possible causes of the incidence increase overestimation," Ceskoslovenská Patologie, vol. 45, no. 2, pp. 50-52, 2009.

[6] S. V. Jargin, "Overestimation of thyroid cancer incidence after Chernobyl," Health Physics, vol. 96, no. 2, p. 186, 2009.

[7] S. V. Jargin, "Overestimation of Chernobyl consequences: biophysical aspects," Radiation and Environmental Biophysics, vol. 48, no. 3, pp. 341-344, 2009.

[8] S. V. Jargin, "Chernobyl-related cancer: re-evaluation needed," Turkish Journal of Pathology, vol. 26, no. 2, pp. 177-181, 2010.

[9] S. V. Jargin, "Validity of thyroid cancer incidence data following the chernobyl accident," Health Physics, vol. 101, no. 6, pp. 754-757, 2011.

[10] D. Williams, "Radiation carcinogenesis: lessons from Chernobyl," Oncogene, vol. 27, supplement 2, pp. S9-S18, 2008.

[11] H. M. Rabes, E. P. Demidchik, J. D. Sidorow et al., "Pattern of radiation-induced RET and NTRK1 rearrangements in 191 post- Chernobyl papillary thyroid carcinomas: biological, phenotypic, and clinical implications," Clinical Cancer Research, vol. 6, no. 3, pp. 1093-1103, 2000.

[12] Y. E. Nikiforov, "Radiation-induced thyroid cancer: what we have learned from chernobyl," Endocrine Pathology, vol. 17, no. 4, pp. 307-317, 2006.

[13] V. Trovisco, P. Soares, A. Preto, P. Castro, V. Máximo, and M. Sobrinho-Simões, "Molecular genetics of papillary thyroid carcinoma: great expectations," Arquivos Brasileiros de Endocrinologia e Metabologia, vol. 51, no. 5, pp. 643-653, 2007.

[14] E. D. Williams, A. Abrosimov, T. Bogdanova et al., "Thyroid carcinoma after Chernobyl latent period, morphology and aggressiveness," British Journal of Cancer, vol. 90, no. 11, pp. 2219-2224, 2004.

[15] I. Bongarzone, P. Vigneri, L. Mariani, P. Collini, S. Pilotti, and M. A. Pierotti, "RET/NTRK1 rearrangements in thyroid gland tumors of the papillary carcinoma family: correlation with clinicopathological features," Clinical Cancer Research, vol. 4, no. 1, pp. 223-228, 1998.

[16] UNSCEAR, "Exposures and effects of the Chernobyl accident," in Sources and Effects of Ionizing Radiation. Report to the General Assembly. Annex J, United Nations, New York, NY, USA, 2000.

[17] IAEA, "Environmental consequences of the Chernobyl accident and their remediation: twenty years of experience," Report of the Chernobyl Forum Expert Group "Environment", IAEA, Vienna, Austria, 2006.

[18] E. M. Parshkov, "Analysis of thyroid cancer morbidity," in Thyroid Cancer in Russia after the Chernobyl, E. F. Lushnikov, F. Tsyb, and S. Yamashita, Eds., pp. 36-59, Meditsina, Moscow, Russia, 2006.

[19] Z. Jaworowski, "Observations on the chernobyl disaster and LNT,” Dose-Response, vol. 8, no. 2, pp. 148-171, 2010.
[20] T. Mizuno, K. S. Iwamoto, S. Kyoizumi et al., "Preferential induction of RET/PTC1 rearrangement by X-ray irradiation," Oncogene, vol. 19, no. 3, pp. 438-443, 2000.

[21] C. M. Caudill, Z. Zhu, R. Ciampi, J. R. Stringer, and Y. E. Nikiforov, "Dose-dependent generation of RET/PTC in human thyroid cells after in vitro exposure to gamma-radiation: a model of carcinogenic chromosomal rearrangement induced by ionizing radiation," Journal of Clinical Endocrinology and Metabolism, vol. 90, no. 4, pp. 2364-2369, 2005.

[22] T. Ito, T. Seyama, K. S. Iwamoto et al., "In vitro irradiation is able to cause RET oncogene rearrangement," Cancer Research, vol. 53, no. 13, pp. 2940-2943, 1993.

[23] K. Nakachi, T. Hayashi, K. Hamatani, H. Eguchi, and Y. Kusunoki, "Sixty years of follow-up of Hiroshima and Nagasaki survivors: current progress in molecular epidemiology studies," Mutation Research, vol. 659, no. 1-2, pp. 109-117, 2008.

[24] K. Hamatani, H. Eguchi, R. Ito et al., "RET/PTC rearrangements preferentially occurred in papillary thyroid cancer among atomic bomb survivors exposed to high radiation dose," Cancer Research, vol. 68, no. 17, pp. 7176-7182, 2008. 


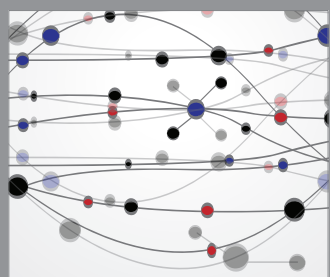

The Scientific World Journal
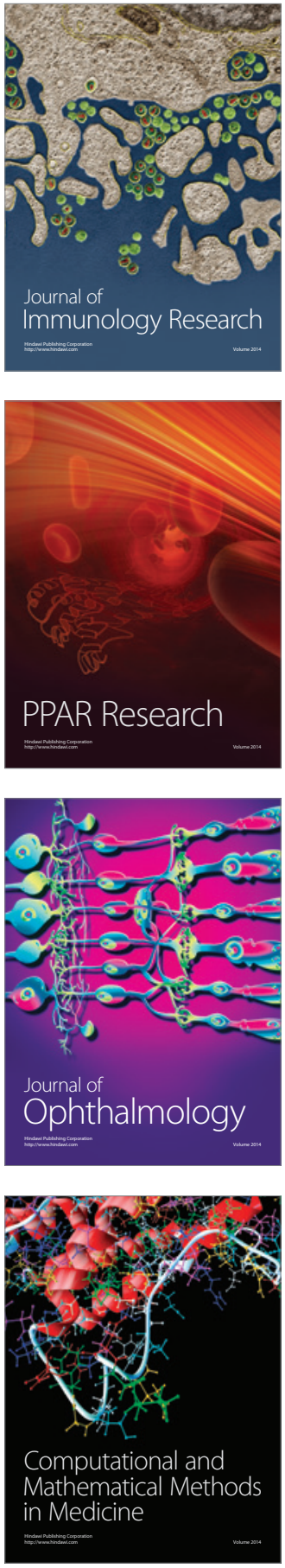

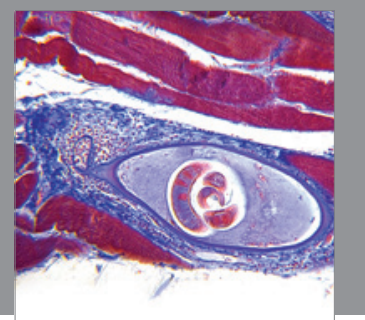

Gastroenterology

Research and Practice
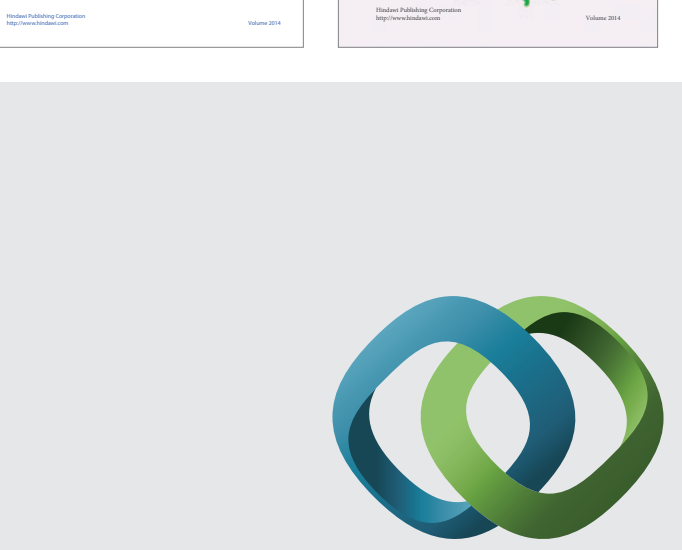

\section{Hindawi}

Submit your manuscripts at

http://www.hindawi.com
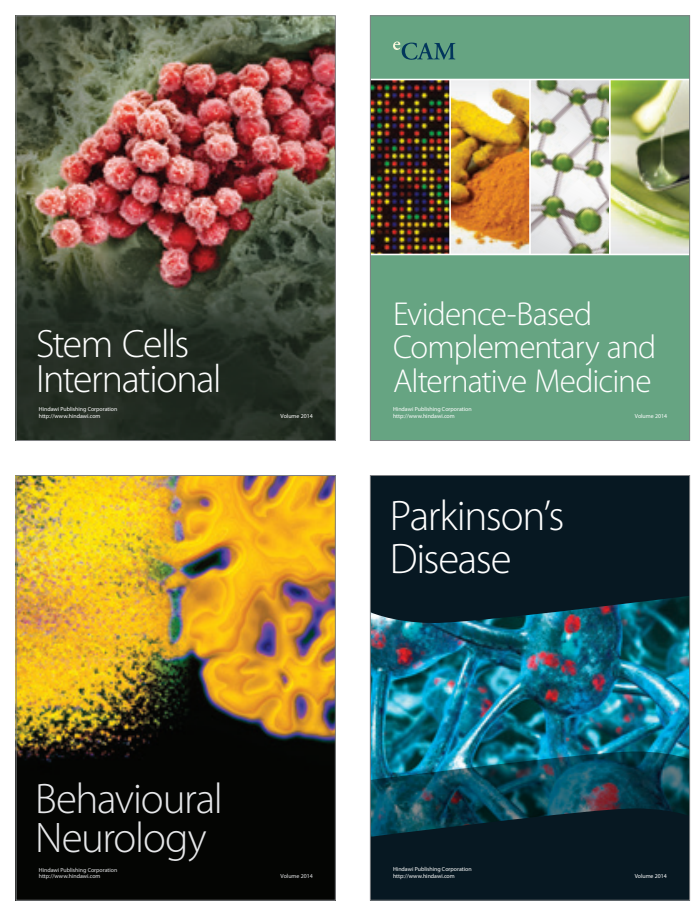

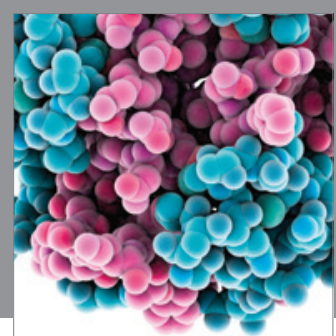

Journal of
Diabetes Research

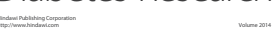

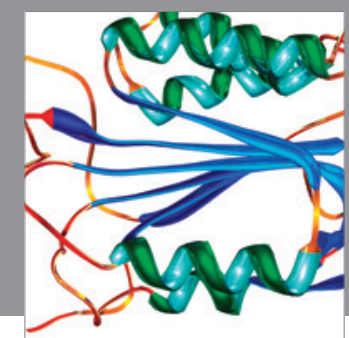

Disease Markers
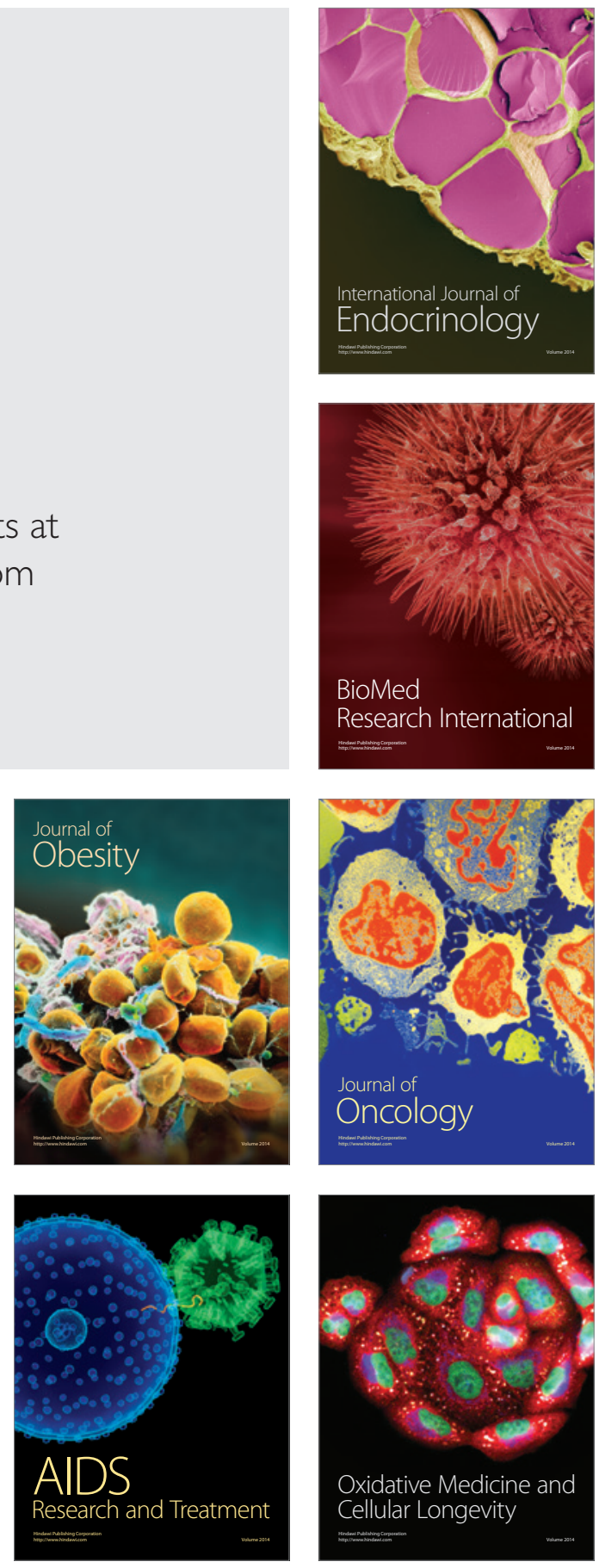